\title{
РЕЦЕНЗІї
}

DOI https://doi.org/10.26661/2414-9594-2021-1-39

\section{REVIEW OF THE MONOGRAPH BY NATALIIA LAZEBNA "ENGLISH LANGUAGE AS MEDIATOR OF HUMAN-MACHINE COMMUNICATION"1}

\author{
Dinesh Kumar \\ Professor \\ Dyal Singh College \\ Karnal, Haryana, India
}

The present book, titled English Language as Mediator of Human Machine Communication is a brilliant attempt by the author to justify the content and subject-matter handled in an efficient manner.

Chapter first, titled Language of Programming as the Linguistic and Mathematical Symbiosis portrays beautifully the socio-cultural characteristics of synthetic language as well as uncanny hyperreal, supernormal virtual relationship and communication: human and non-human.

Chapter Second of the book, The Modern English Language and its Perception by Human throws light on some of the philosophical and logics of English language. The author has brilliantly presented the morphological awareness of humans and its effect on the correct use of words. She has also taken into consideration the assessment of human competence noun phrase construction that will be beneficial for the readers and it will certainly help them in enhancing their understanding regarding these aspects to a great extent.

In Chapter III, English and Non-Human Languages interaction, the author tries to convey the knowledge of said subject by providing an in-depth information about formal relation of information- language objects and artificial intelligence. Besides it, she has also worked hard on the topics of Semantic Ambiguity Machine Ukrainian-English Translation and Semantic Ambiguity of English language Chatbots.

Chapter IV delineates the concept of chatbots as anchors. The author has also dealt with the objective study of chatbots in terms of linguistic, its performance and improvement, as well as pragmatics of chatbots.

In the beginning, the author tries to focus on an intuitive-sensual type. By means of practical skills an individual gets acquainted with language peculiarities. An individual should master language usage and even try to think with the help of studied language. In case

\footnotetext{
${ }^{1}$ Nataliia Lazebna. English Language as Mediator of HumanMachine Communication : monograph. Mysore, India : PhDians along with Ambishpere ; Academic and Medical Publishers ; Royal Book Publishing, 2021. 571 p.
}

an individual is characterized by an intuitive-sensual type of language acquisition, he masters his skills by ear or within a special language environment. The main difficulty is to master phonetics and semantic charge of foreign words.

While explaining abilities of children to distil syntactic patterns from the speeches of their parents or people around them, in the present book, the author has taken into consideration a universal perspective.

She has quoted a number of examples from well-known and reputed linguists including Naom Chomsky and Pinker, which helps in differentiating human language from the non-human language on the basis of design features of the language. It reflects the idea how the human language reaches indefinite scope of influence by means of definite tools. On the one hand, whereas in non-humans the vocal calls are located in other parts of brains, but on the other hand, in case of human brains the in-born peculiarities are responsible for language "location". The author has also tried to propound the conviction how human communication has been developed in accordance with the special needs of humans and as a response to a changing reality.

In case of non-human, language abilities were not developed as much because they do not require such adaptation. Still, the author does not find non- human disabilities to communicate the same way as humans do, but she underlines that communication among humans and non-humans should not be equal, as the bird's wings should not be equal to human hands.

All in all, the present book will be very useful for the English-language students and learners and will purvey to the need of those who passionately desire to get in depth, minute and microscopic knowledge of English Language and the various aspects associated with it.

Moreover, various articles used by the author also make the reader convince and to get a wider perspective of the English language. In these articles, the article titled, "Is language unique to the human species?" by Ulla Hedeager provides ample knowledge where the author intends to claim that 
language is universal both for humans and nonhumans. Nevertheless, the main difference between human and non-human communication is considered by the author in terms of predictability of animals in the process of communication and unpredictability of human language. Other articles by various linguists such as Charles Hockett and Chomsky are considered to be improper in terms of natural social context.

The author has also tried to present a very comprehensive account of English language and the tools associated with it through advocating three different approaches and perspectives in which Psychological Perspective, Social Perspective and Biological Perspective help to get a deep insight into the English language and factors associating with it when we learn it. Individual psychological features define strategies of language acquisition.

Psychologists study verbal and non-verbal ways of storing, generating and transmitting information in the consciousness of individuals and societies. For example, common and distinctive features of lexical and semantic systems in different languages are under consideration. For native speakers and foreigners, semantic, grammar or other linguistic features can differ. The researchers claim that language is an individual psychic act, a phenomenon of psychological activity of a person or people. Every individual refers to his own language, where he reflects his personal and ethnic specifics. The environment of an individual shapes his language acquisition process. As a rule, it is possible to outline two basic psychological aspects of language acquisition: intuitive-sensual and rational-logic.

When individuals use foreign words and expressions in their native speech, they switch from native language to foreign language involuntarily. Rational-logical type of language acquisition requires theoretical linguistic knowledge and very often results in many difficulties of language mastering. This aspect focuses on grammar structures and vocabulary mastering. Despite differences in psychological aspects of language acquisition, it is possible to reach effective communication in case speakers are open-minded, ready to share their experience with other speakers and focus on common goals of communication.

There is another challenge, when an individual changes his language perception under the influence of foreign language environment. In this case, a foreigner's cognitive abilities are under pressure. Individual psychological reality subject to foreign language environment. Language acquisition is a complex and challenging process, which involves both heart and mind of an individual. Effective individual psychological aspect of language acquisition depends on both intuitive- sensual and rational-logic language perception, as well as environment of speakers.

Through the biological perspectives, the author has tried to connect the study of language biological aspects. For a long time, there has been a hot discussion among many researchers and scientists that language is a biological phenomenon. From their viewpoint, it is an innate property of a person, the same as the ability of a person to eat, drink, walk, etc. In other words, language is inherited by humans. It is inherent in the biological entity of humans. On the other hand, we can witness many examples in nature, when children turn into wild beasts or animals if they grew up among them. When these children returned to human society, they could not learn to speak although their organs of speech were quite normal. Moreover, there are many examples, when children of one nationality were placed into another language environment, and they spoke the language of the environment, and not their native language. These facts show that language is not inherited and does not belong to biological phenomena. As far as we can see, biological perspective can be argued.

Last, but not the least, the writer has tried to incorporate the social aspects in the learning of English language. Social aspect of language acquisition is given by LeMonda which contrasts with the biological aspect of language. The researchers claim that responsiveness of parents in the process of child's language acquisition results in effective words learning and vocabulary development. The researchers explain interaction between parents and their children as an effective background for socialization. A child understands that if he repeats one or another word, he will find a responsive reaction to his activities. Further, children can refer the words they hear to the objects from real life. Thus, they will extend the process of their socialization. Pragmatic understanding of meaning conveyed by words will extend referents' background for children.

Without any shadow of doubt, the present book, ENGLISH LANGUAGE AS MEDIATOR OF HUMAN-MACHINE COMMUNICATION will be beneficial for those who want to expose themselves to the English language and the tools associated with it which will surely help the readers to grasp a better understanding and more comprehensive study of English Language. 